1 Revised Journal Paper Submission: Water Research

2

3 Journal Paper Type: Technical Research Paper

4

5 Paper Title:

6 Stabilization of Benthic Algal Biomass in a Temperate Stream Draining Agroecosystems

7

8 Authors:

9 William I. Ford and James F. Fox, University of Kentucky, Lexington, Kentucky, United States

10

11 Running Title:

12 Stabilization of Benthic Algal Biomass

13

14 Keywords:

15 algal stabilization, agroecosystems, fluvial carbon budget, watershed model

16

(c) 2016. This manuscript version is made available under the Elsevier user license

http://www.elsevier.com/open-access/userlicense/1.0/ 


\section{Stabilization of Benthic Algal Biomass in a Temperate Stream Draining Agroecosystems}

William I. Ford ${ }^{1 *}$, James F. Fox ${ }^{2}$

ABSTRACT

Results of the present study quantified carbon sequestration due to algal stabilization in low order streams, which has not been considered previously in carbon stream ecosystem studies. The authors used empirical mode decomposition of an 8-year carbon elemental and isotope dataset to quantify carbon accrual and fingerprint carbon derived from algal stabilization. The authors then applied a calibrated, process-based stream carbon model (ISOFLOC) that elicits further evidence of algal stabilization. Data and modeling results suggested that processes of shielding and burial during an extreme hydrologic event enhance algal stabilization. Given that previous studies assumed stream algae are turned over or sloughed downstream, the authors performed scenario simulations of the calibrated model in order to assess how changing environmental conditions might impact algae stabilization within the stream. Results from modeling scenarios showed an increase in algal stabilization as mean annual water temperature increases ranging from 0 to $0.04 \mathrm{tC} \mathrm{km}^{-2}{ }^{\circ} \mathrm{C}^{-1}$ for the study watershed. The dependence of algal stabilization on temperature highlighted the importance of accounting for benthic fate of carbon in streams under projected warming scenarios. This finding contradicts the evolving paradigm that net efflux of $\mathrm{CO}_{2}$ from streams increases with increasing temperatures. Results also quantified sloughed algae that is transported and potentially stabilized downstream and showed that benthos-derived sloughed algae was on the same order of magnitude, and at times greater, than phytoplankton within downstream water bodies.

KEYWORDS: algal stabilization, agroecosystems, fluvial carbon budget, watershed model

\footnotetext{
* Corresponding Author: Division of Engineering, Marshall University, Huntington, WV 25705, USA; Phone: +1(304)696-5664; Email: fordw@ marshall.edu 1 Assistant Professor, Division of Engineering, Marshall University 2Professor, Civil Engineering Department, University of Kentucky
} 


\section{1) INTRODUCTION}

Highly disturbed agroecosystem streams demand scientific investigation because they have broad spatial extent, hold significant weight within the freshwater carbon budget, and partially govern downstream carbon cycling (Butman and Raymond, 2011; Griffiths et al., 2012; Ford and Fox, 2014a). Agroecosystem streams often starkly contrast forested and steep gradient systems because they have open canopies that promote high light availability to streambeds for benthic algae production, upland agriculture that produces high nutrient inputs, and low stream gradients that facilitate benthic storage of organic matter and bacterial biofilms (Rutherford et al., 2000; Griffiths et al., 2012; Ford and Fox, 2014a). In turn, low-gradient agroecosystem streams harbor autochthonous carbon within bed sediments that can cause streambeds to have a high amount of stored carbon, a wide carbon pool distribution, and a highly variable stream carbon flux across events seasonally and annually (Dalzell et al., 2005; Griffiths et al., 2012; Ford and Fox, 2014a,b; Ford et al., 2014; Fox et al., 2014). However, to our knowledge, no previous studies use long-term carbon datasets or numerical modeling to quantify $\mathrm{C}$ sequestration from algal stabilization in agroecosystem streams.

Algal stabilization is the coupled biotic-abiotic process by which algal biomass decomposes into more complex refractory carbon compounds in aquatic ecosystems for extended periods (Lara and Thomas, 1995; Leloup et al., 2013; Hotchkiss and Hall, 2015). At the watershed-scale, numerical models for fluvial carbon budgets broadly neglect contributions of algal stabilization to benthic carbon storage since the models treat benthic carbon as a $10 \mathrm{~cm}$ hydro-dynamically static anaerobic layer (DiToro, 2001; Wool et al., 2006; Chapra et al., 2008; Park and Clough, 2012). In part, scientists support this assumption with the argument that algal biomass has a net zero effect on fixation and respiration in fluvial carbon budgets due to its short 
64 turnover lengths and a tendency for algal carbon to fuel ecosystem services (Minshall et al.,

65 1983; Griffiths et al., 2012; Hotchkiss and Hall, 2015). However, as stated previously, few, if 66 any studies, use long-term $\mathrm{C}$ records to investigate this assumption.

The effect of long-term temperature shifts and extreme hydrologic events on algal stabilization and $\mathrm{C}$ sequestration is of particular interest given that flow regime and water temperature are two critical drivers of algal carbon dynamics in disturbed agroecosystems (e.g., Rutherford et al., 2000; Flynn et al., 2013). Flow regime has the potential to impact algal

71 stabilization through episodic sloughing and downstream export of benthic periphyton, fluvial 72 erosion of stabilized algae in the benthos, and burial of stabilized algae due to depositional fluxes 73 (Droppo and Stone, 1994; Fovet et al., 2010; Graba et al., 2013; Flynn et al., 2013; Ford and Fox, 74 2014a). Since temperature is the primary biotic variable controlling algal production and the 75 microbial decomposition of coarse and stabilized algal pools, agroecosystems often have non76 rate-limiting nutrient and light conditions (Rutherford et al., 2000; Griffiths et al., 2012; Ford and 77 Fox, 2014). Recent studies suggest temperature gradient increases will promote decreases in net 78 carbon sequestration by freshwater streams based on the argument that biotic respiration is more 79 sensitive to temperature than autotrophic production (Yvon Durocher et al., 2010; Trimmer et al., 80 2012). However, these previous studies focused on short timescales and mesocosm-based experimentation due to the difficulties in obtaining long-term ambient datasets.

The objective of this study was to quantify $\mathrm{C}$ sequestration in agroecosystem streams as a 83 result of algal stabilization. The authors apply an eight-year dataset of stream $\mathrm{C}$ elemental and 84 isotope signatures to provide evidence of algae stabilization. Then, the authors apply a process85 based stream $\mathrm{C}$ model to provide further evidence of algal stabilization and elucidate the physical 86 and biological processes that govern algal stabilization. Next, the authors then use the process- 
87 based model to simulate how changing temperature and extreme hydrologic conditions provide 88 external control on algae stabilization. Finally, the numerical simulations allow the authors to discuss existing paradigms of temperature variability on stream $\mathrm{CO}_{2}$ efflux and the impacts of algal sloughing to downstream ecosystems.

\section{2) STUDY SYSTEM: AGROECOSYSTEM STREAM}

The 62-km² South Elkhorn watershed (Figure 1) was chosen as a study site of algal stabilization because of the extensive knowledge of land use, flow, sediment and carbon dynamics in the system; the highly productive nature of the streambed; and the spatial and temporal variability of the dynamic benthos (Fox et al., 2010; Russo and Fox, 2012; Ford and Fox, 2014a; Ford and Fox, 2014b; Fox et al., 2014; Ford et al., 2014; Ford et al., 2015; Ford and Fox, 2015). The South Elkhorn watershed is located in the Bluegrass Region of Central Kentucky and is a mixed-use watershed that is impacted by agricultural and urban land use. During the decade-long time period of water quality data collection, the agricultural land use (57\%) was primarily horse farms, while urban land use (43\%) was primarily residential and commercial. Storm flows drove precipitation, and subsequently streamflow and produced 1150 $\mathrm{mm} /$ year of precipitation and an average stream flow rate of $1.2 \mathrm{~m}^{3} \mathrm{~s}^{-1}$. The study site had an average daily temperature of $13.1^{\circ} \mathrm{C}$ and experienced four distinct seasons. Silty clay loam soils in the watershed produced fine sediments $(d=20 \mu \mathrm{m}$, where $d$ is the average particle diameter) from the watershed's landscape that were a significant component of the transported sediment load in the streams (Fox et al., 2014). During the study period, the South Elkhorn watershed had 53 perennial stream reaches: 27 first order, 13 second order and 13 third order. 


\section{3) METHODS}

111

112

113

114

115

116

117

118

119

120

121

122

123

124

125

\subsection{Empirical Mode Decomposition of the Carbon Time-Series:}

The authors monitored carbon dynamics in the agroecosystem stream using an eight-year dataset of transported sediment carbon that was subsequently post-processed with empirical mode decomposition time-series analysis (Ford and Fox, 2014a; Ford et al., 2014; Ford et al., 2015). Briefly, the authors collected transported sediment samples from the outlet of the study watershed on a weekly basis (Figure 1) utilizing in situ sediment traps (Phillips et al., 2000). The authors processed all samples at the University of Kentucky Hydraulics Laboratory by decanting, centrifuging, freezing, and freeze-drying to remove remaining water. The bulk freeze-dried samples were sub-sampled depending on mass; wet-sieved to retain the fines fraction; ground and weighed into silver capsules; and acidified with 6\% sulfurous acid to remove carbonate phases (Verardo et al., 1990; Ford and Fox, 2014a). Transported sediment samples were analyzed for elemental compositions of fine particulate organic carbon $\left(C_{F P O C-T}\right)$ and its isotopic signature $\left(\delta^{13} C_{F P O C-T}\right)$ by combusting samples at $980^{\circ} \mathrm{C}$ on a Costech 4010 Elemental Analyzer and then passing the gas stream through a Gas Chromatograph (GC) column ( $3 \mathrm{~m} \mathrm{HS}-\mathrm{Q}$ ) to a Thermo Finnigan Delta-Plus XP Isotope Ratio Mass Spectrometer (IRMS).

The authors performed empirical mode decomposition of the eight-year sediment carbon dataset using a time-series analyses outlined in Ford et al. (2015). In the present study, the authors emphasize the long-term residual trends from empirical mode decomposition (EMD), which have not been discussed previously, in order to study long-term sequestration of carbon via algal stabilization. Empirical mode decomposition is a non-linear, non-stationary time-series analysis method that decomposes a dataset into a series of intrinsic mode functions, or IMFs (Haung et al., 1998; Wu et al., 2007). IMFs are a finite series of amplitude and frequency modulated, oscillatory functions in which the lowest frequency intrinsic mode function is the 
134 base trend and the highest frequency trend is considered noise for well-sampled datasets (Wu et 135 al., 2007). As discussed in Ford et al. (2015), the authors performed empirical mode 136 decomposition using a six step iterative procedure in which the dataset $X(t)$ was represented as:

$X(t)=\sum_{i=1}^{n} c_{i}+r_{n}$

137 where, $c_{\mathrm{i}}$ were the IMFs, and $r_{n}$ was the residual noise following the coarsest frequency trend.

138 The coarsest frequency trend was the particular trend of interest for the current work.

\subsection{Deterministic Modeling of Stream Carbon Dynamics:}

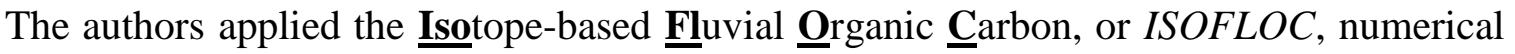

142 model to further investigate the prevalence of algal stabilization and its governing processes.

143 ISOFLOC is a process-based stream $\mathrm{C}$ model that simulates both terrestrial and autochthonous

144 carbon fate and transport within the stream corridor. Additionally, ISOFLOC simulates multiple

145 dissolved and particulate carbon pools and their transformations. Ford and Fox's study (2015)

146 details ISOFLOC's model formulation, sensitivity, and calibration procedure and provides a

147 detailed list of inputs and parameters with justified ranges for application of ISOFLOC specific

148 to the South Elkhorn watershed. In the next paragraphs, the authors provide a brief synopsis of

149 ISOCFLOC's description and applicability to simulate algal stabilization.

ISOFLOC includes water and sediment transport subroutines that provide the basis for

151 advective transport simulation of dissolved carbon and particulate carbon pools within the

152 agroecosystem stream. In the present study, ISOFLOC used carbon mass-balance equations to

153 simulate growth and turnover of periphyton. ISOFLOC also used numerical simulation of both

154 the surficial fine-grained laminae (SFGL) and dissolved inorganic carbon simultaneously to 
155 estimate coupled feedbacks between the carbon pools. Inclusion of the multiple pools within 156 ISOFLOC allowed continuous simulation of autochthonous generation as well as microbial 157 associated decomposition of the heterogeneous organic carbon mixtures within the streambed 158 storage deposits. ISOFLOC continuously accounted for physical and biogeochemical processes 159 impacting each pool, thus allowing the authors to integrate processes after simulations were 160 complete. The authors then investigated net processes that control stream ecosystem dynamics 161 and algal stabilization at different timescales. ISOFLOC continuously simulated stable carbon

162 isotope mass balances with Rayleigh fractionations for periphyton $\left(\delta^{13} C_{\text {Periphyton }}\right)$, SFGL carbon $163\left(\delta^{13} C_{S F G L}\right)$, and dissolved inorganic carbon $\left(\delta^{13} C_{D I C}\right)$ pools. ISOFLOC estimated elemental 164 signatures of transported sediment carbon $\left(C_{F P O C-T}\right)$ and isotopic signatures of transported 165 sediment carbon $\left(\delta^{13} C_{F P O C-T}\right)$ using mass balances that calculate the carbon weighted average of 166 source contributions and their associated elemental (i.e., $C_{S F G L}, C_{U p l a n d}$, and $C_{B a n k}$ ) and isotopic 167 signatures (i.e., $\delta^{13} C_{S F G L}, \delta^{13} C_{U p l a n d}$, and $\delta^{13} C_{B a n k}$ ). A total of eight potentially sensitive 168 parameters were specified for the stable isotope sub model in ISOFLOC including three input 169 parameters measured at the study site $\left(\delta^{13} C_{D I C-I N,}, \delta^{13} C_{U p l a n d}, \delta^{13} C_{\text {Bank }}\right)$ and five literature 170 parameters $\left(\delta^{13} C_{\text {Atmosphere, }} \varepsilon_{D E C-F P O C}, \varepsilon_{D E C-A P O C}, \varepsilon_{\text {Assimilation-Max }}, \varepsilon_{\text {Evasion }}\right)$. In turn, the authors 171 calibrated and validated the ISOFLOC outputs against the aforementioned eight-year organic 172 carbon dataset $\left(C_{F P O C-T}\right.$ and $\left.\delta^{13} C_{F P O C-T}\right)$. We refer the reader to Ford and Fox (2015) for full 173 description of the South Elkhorn model parameterization and uncertainty analysis. The authors performed model uncertainty analysis of ISOFLOC in order to generate a 175 posterior solution space that was highly robust in its estimates of the fluvial sediment organic 176 carbon budget. The authors performed 30,000 ISOFLOC simulations driven by semi-random 177 Sobol sequences of the model parameter inputs (Sobol, 2001; Saltelli et al., 2010). The authors 
178 based acceptable model performance for the posterior solution space on widely-used statistical 179 metrics in water quality modeling, which include the root mean square error of the standard 180 deviation of measured data (RSR), Nash-Sutcliffe efficiency (NSE), and percent bias (PBIAS) 181 (Moriasi et al., 2007). The authors included model configurations in the posterior solution space 182 when the following conditions were met: $\mathrm{RSR}<0.8$ and NSE $>0.4$ for calibration ( $2 / 3$ of the data) 183 and validation (1/3 of the data) of the sediment carbon content signatures $\left(C_{F P O C-T}\right)$ and $\mathrm{RSR}<1$ 184 and NSE $>0$ for calibration and validation of the sediment carbon isotopic signatures $\left(\delta^{13} C_{F P O C-T}\right)$. 185 The authors enforced a PBIAS threshold of $\pm 20 \%$ to ensure model simulations did not 186 consistently over or underestimate measured data. The specified statistics ensured that the model 187 outputs provided superior goodness-of-fit to a mean trend suggesting that each of the acceptable 188 model simulations reflected the underlying processes. Table 1 compiles ranges for model 189 parameters of the scenarios meeting these criteria. It should be noted that uncertainty for the fine 190 particulate organic carbon pool and the associated algal stabilization dynamics were fairly 191 narrow due to the sensitivity of the model response variables $\left(C_{F P O C-T}\right.$ and $\left.\delta^{13} C_{F P O C-T}\right)$ to those 192 dynamics. For this reason, the authors felt confidence in the optimized scenario that provided $193 \mathrm{RSR}<0.8$, NSE $>0.4$, and $\mathrm{PBIAS}<10 \%$ for all calibration and validation datasets (see Table 1 ).

\subsection{Model Analysis of Changing Temperatures and Hydrologic Events:}

The authors questioned what physical and biological controls might impact net carbon 197 sequestration via algal stabilization. The non-linearity of physical and biogeochemical processes 198 within the water column and surficial fine-grained laminae of ecosystems streams obfuscate the 199 drivers of the carbon sequestration using data alone (Ford and Fox, 2015). However, the authors 200 had the advantage of using the validated ISOFLOC model to test external physical and biological 201 controls via scenario analysis. Specifically, the authors investigated temperature variation and 
202 hydrologic extremity over the data collection and simulation periods given the prevalence of 203 temperature and extremes to control stream processes (Peterson, 1996; Rutherford et al., 2000; 204 Davis et al., 2013; Ford et al., 2015).

As a precursor to ISOFLOC model scenario analyses of temperature variation and hydrologic extremity analyses, the authors performed pre-modeling analyses of existing temperature and water flowrate data. The authors downloaded temperature data from a NOAA weather station at the Lexington Bluegrass Airport located within the center of the study basin. 209 The authors analyzed monthly average temperatures from 1964 to the present in order to 210 minimize effects associated with boundary conditions for the analysis. An Empirical Mode 211 Decomposition for the 50-year time-series revealed statistically significant seasonal and decadal 212 IMFs assuming noise greater than two standard deviations as criteria for statistically significant 213 trends (Figure 2). Statistical criteria provided a 95\% confidence interval for the temperature 214 results. The authors also performed a storm frequency analysis using precipitation data from the 215 basin's gauging station. A storm event in September, 2006 produced peak hourly, bihourly, and 216 daily rainfalls of $2.1,3.9$ and 6.2 inches, respectively, which fell within the $90 \%$ confidence 217 interval for a 100 year return interval based on the NOAA precipitation frequency data server for 218 the Lexington Bluegrass Airport. The quantitative hydrologic analyses for the 2006 event also 219 agreed well with the previous research by Ford et al. (2014), which showed that the 2006 storm 220 event induced SFGL dis-equilibrium with regard to sediment carbon quality, which is likely 221 tightly linked to SFGL algae dynamics.

Based on pre-modeling data analyses that showed residual temperature variation and 223 hydrologic extremity in 2006, the authors tested the potential importance of the physical 224 (hydrologic) and biological (temperature) controls upon carbon sequestration via algal 
225 stabilization using ISOFLOC. The authors used ISOFLOC to simulate the impact of the decadal

226 residual temperature trend on surficial fine-grained laminae carbon stock and, subsequently,

227 transported sediment carbon. The fluctuation in air temperature was augmented to account for

228 the relationship between air temperature and water temperature in the study region and was then

229 removed from the input time series utilized for model simulations. Additionally, the authors

230 propagated the de-trended temperature time series through the ISOFLOC model. The authors ran

231 additional simulations with variable temperatures to further show how temperature conditions

232 might promote carbon sequestration through chronic increase and buildup of stabilized algae in

233 the surficial fine grained laminae. The authors simulated four scenarios with a 2 and $4^{\circ} \mathrm{C}$ upward

234 shift in water temperature and 2 and $4^{\circ} \mathrm{C}$ downward shift in water temperature. The authors

235 compared results from the scenarios ran to the calibrated scenario for baseline reference. Finally,

236 to test the importance of the hydrologic control, the authors removed the 2006 storm event from

237 the input flow dataset for model simulation in ISOFLOC by assuming base flow conditions

238 throughout the duration of the event.

As an aside, the authors point out to the reader that they also investigated other potential drivers of carbon sequestration for the studied stream, which were subsequently marginalized

241 with respect to their influence. With regard to light availability, the authors analyzed National 242 Renewable Energy Laboratory (NREL) data for the Bluegrass airport from 1990-2010 using an 243 Empirical Mode Decomposition (EMD analysis. No significant trends were observed at a 244 decadal timescale and the long-term residual IMF was stationary. Similarly, EMD analysis of 245 flowrate showed no distinct long-term trends that would impact carbon dynamics (Ford et al., 246 2015). Nutrient conditions for the study site were reported elsewhere (Ford et al., 2015) and 247 showed that levels of rate-limiting macronutrients (e.g., phosphates and nitrates) were above 
248 minimum thresholds for rate-limiting nutrient conditions (Dodds, 2007). Finally, land-use 249 remained fairly constant in the watershed during the study time period aside from some 250 urbanization at the upstream site of the main-stem in early 2006.

\section{4) RESULTS}

\subsection{Empirical Mode Decomposition of the Carbon Time-Series:}

Long-term residual trends for transported sediment carbon $\left(C_{F P O C-T}\right)$ and transported

sediment carbon isotope signatures $\left(\delta^{13} C_{F P O C-T}\right)$ were non-stationary over the eight-year data collection period based on the Empirical Mode Decomposition (EMD) results (Figure 3). With regard to transported sediment carbon, results of the EMD analysis showed a net increase from a minimum transported sediment carbon $\left(C_{F P O C-T}\right)$ value of $2.4 \%$ in 2007 to a maximum of $3.9 \%$ in 2012 , resulting in a $65 \%$ enrichment in transported sediment carbon $\left(C_{F P O C-T}\right)$ at the watershed

262 showed a net decrease from a maximum transported sediment carbon isotope signature $263\left(\delta^{13} C_{F P O C-T}\right)$ of $-26.3 \%$ in 2007 to a minimum of $-27.3 \%$ at the end of the monitoring period, 264 resulting in a $1 \%$ decrease in transported sediment carbon isotope signature $\left(\delta^{13} C_{F P O C-T}\right)$ at the 265 watershed outlet (Figure 3b).

\subsection{Deterministic Modeling of Stream Carbon Dynamics:}

Long-term carbon dynamics simulated in ISOFLOC for the South Elkhorn Watershed

269 regard to the carbon mass-balance model, ISOFLOC results showed an average annual 270 transported sediment carbon $\left(C_{F P O C-T}\right)$ value of $2.6 \pm 0.4 \%$ in 2007 that increased to $3.4 \pm 0.4 \%$ in

2712012 , resulting in a $32 \%$ enrichment in transported sediment carbon $\left(C_{F P O C-T}\right)$ at the watershed 
272 outlet (Figure 3a). With regard to the stable isotope model, ISOFLOC results showed an average 273 annual transported sediment carbon isotope signature $\left(\delta^{13} C_{F P O C-T}\right)$ of $-25.7 \pm 0.2 \%$ in 2007 that 274 decreased to $-27.3 \pm 0.3 \%$ in 2012 , resulting in a $1.5 \%$ decrease in the transported sediment 275 carbon isotope signature $\left(\delta^{13} C_{F P O C-T}\right)$ at the watershed outlet (Figure 3b).

Seasonal and annual ISOFLOC model carbon budget results, including fluxes and benthic 277 carbon storage within periphyton and SFGL pools, quantified carbon fate and transport for the 278 study period (see Table 2). The calibrated ISOFLOC model showed an advective flux of $0.98 \mathrm{tC}$ $279 \mathrm{~km}^{-2} \mathrm{yr}^{-1}$ for sloughed periphyton and erosion of stabilized SFGL algae equaling $0.088 \mathrm{tC} \mathrm{km}^{-2}$ $280 \mathrm{yr}^{-1}$. Of particular interest was the modelling result that $0.013 \mathrm{tC} \mathrm{km}^{-2} \mathrm{yr}^{-1}$ of stabilized algae 281 accrued on average in the SFGL each year. Seasonally, stabilized algae storage was highest 282 during spring and summer when periphyton sloughing was low. SFGL stabilized algal carbon 283 respiration outweighs stabilization of periphyton to the SFGL in fall and winter when standing 284 stocks of periphyton became temperature limited. Annually, stabilized algal carbon storage in 285 the SFGL was lowest in years when both periphyton sloughing and stabilized algal SFGL flux 286 via erosion was high (i.e., 2009, 2011 and 2013). In 2006 when stabilized algae in the SFGL 287 was low, and thus stabilized algal SFGL flux via erosion was low, net storage was above average 288 because inputs of algal stabilization exceeded fluxes of erosion and decomposition of existing 289 SFGL stabilized algae.

The authors integrated ISOFLOC results and tabulated (see Table 3) annual SFGL algal 291 carbon production and fluxes in order to assess dominant processes impacting carbon storage. 292 ISOFLOC results suggest that SFGL stabilized algal carbon was produced at a rate $0.19 \pm 0.02 \mathrm{tC}$ $293 \mathrm{~km}^{-2} \mathrm{yr}^{-1}$ by decomposition of periphyton. Stabilized algal carbon in the SFGL decomposed at a 294 rate of $0.086 \pm 0.013 \mathrm{tC} \mathrm{km}^{-2} \mathrm{yr}^{-1}$ and eroded at a rate of $0.088 \pm 0.033 \mathrm{tC} \mathrm{km}^{-2} \mathrm{yr}^{-1}$ resulting in the 
295 aforementioned stabilized algal net storage of $0.013 \mathrm{tC} \mathrm{km}^{-2} \mathrm{yr}^{-1}$. ISOFLOC results suggest that 296 physical erosion dynamics of SFGL stabilized algae have a broader range of variability (0.05 to

$\left.2970.13 \mathrm{tC} \mathrm{km}^{-2} \mathrm{yr}^{-1}\right)$ than biological decomposition dynamics $\left(0.06\right.$ to $\left.0.10 \mathrm{tC} \mathrm{km}^{-2} \mathrm{yr}^{-1}\right)$.

\subsection{Model Analysis of Changing Temperatures and Hydrologic Events:}

In order to visually (see Fig 4) and quantitatively highlight the impact of algal stabilization on benthic carbon storage and fluxes, the authors ran comparative simulations with ISOFLOC under the calibrated scenario and a scenario where algal dynamics were turned off (i.e., $\left.P_{M a x}=0\right)$. As seen in Figure 4a, initial differences between the calibrated and no algae scenario were a result of the warmup period for the model (2005-2006) that allowed the algal carbon to build up in the SFGL. Initially, the difference in benthic carbon stock was 11 tC; however, by the end of the model scenario the difference was nearly doubled providing visual evidence of the budget findings in Table 2. The resultant impact on the transported sediment carbon content $\left(C_{F P O C-T}\right)$ is shown in Figure $4 \mathrm{~b}$. For the no algae scenario, it was visually evident that transported sediment carbon content $\left(C_{F P O C-T}\right)$ oscillated about $2 \mathrm{gC} / 100 \mathrm{gsed}$, while transported sediment carbon content $\left(C_{F P O C-T}\right)$ for the calibrated scenario steadily rose to approximately $3.2 \mathrm{gC} / 100 \mathrm{gsed}$ by the end of the eight-year simulation.

As mentioned in the methods section, the authors next performed a set of scenario analyses with ISOFLOC to investigate if physical or temperature controls had a greater impact on stabilized algal carbon (Figure 5). First, the authors simulated the variation of the water 315 temperature control by using a detrended temperature time-series (Figure 2). ISOFLOC 316 simulated results for benthic carbon stock, transported sediment carbon content $\left(C_{F P O C-T}\right)$, and 317 transported sediment carbon isotope signature $\left(\delta^{13} C_{F P O C-T}\right)$ utilizing the detrended temperature 
time-series as a model input. Removal of the temperature trend produced a simulated decrease of

$3191 \mathrm{tC}$ in the benthos or a $6.5 \%$ decrease in the storage capacity relative to the baseline calibration

320 simulation. As a result, the transported sediment carbon $\left(C_{F P O C-T}\right)$ at the watershed outlet

321 showed a residual decrease in carbon content (Figure 5b) and an increase in isotopic signature

322 (Figure 5c) due to a larger proportion of upland soil organic carbon in the benthos.

Second, the authors considered hydrologic control through removal of the September

3242006 event (Figure 5d-f). ISOFLOC results showed seasonal fluctuations of benthic FPOC,

325 consistent with the baseline model run. However, the benthic stock gradually decreased resulting

326 in a net loss — rather than accrual — of stabilized algal carbon to the SFGL (Figure 5d). ISOFLOC

327 results suggest that transported sediment carbon content $\left(C_{F P O C-T}\right)$ and transported sediment

328 carbon isotope signature $\left(\delta^{13} C_{F P O C-T}\right)$ were relatively static over long timescales due to the loss of 329 stabilized algae (see Figure 5e-f).

Finally, the authors performed another set of scenarios with ISOFLOC to investigate to

331 what extent more pronounced temperature shifts might have impacted stabilized algal accrual.

332 The increasing shifts in simulated water temperature resulted in a net increase in storage relative

333 to the calibrated scenario. A downward shift in simulated water temperature resulted in a net

334 decrease in storage relative to the baseline calibration scenario (see Figure 6). Similarly, when

335 comparing the downward shifts in simulated water temperature, the $2^{\circ} \mathrm{C}$ shift had a smaller

336 decrease in net storage relative to the $4^{\circ} \mathrm{C}$ shift. Somewhat unexpectedly, the $2^{\circ} \mathrm{C}$ scenario

337 produced a higher net storage of stabilized algal carbon compared to the $4^{\circ} \mathrm{C}$ shift. Furthermore, 338 differences between stabilized algal carbon storage for the decreasing temperature scenarios were much greater than net differences between increasing temperature scenarios. 


\section{5) DISCUSSION}

\subsection{Algal Stabilization in Streams Draining Agro-ecosystems:}

Results of the study provide the first watershed-scale evidence of algal stabilization to

344 produce long-term net sequestration of benthic algal biomass in streams draining agro-

345 ecosystems. Both the data-driven results from empirical mode decomposition and the process-

346 based numerical modeling results from ISOFLOC showed a net increase in carbon from early

347 years (2006-2008) to later years (2010-2013) over the eight-year period transported sediment 348 carbon $\left(C_{F P O C-T}\right)$ was studied (Figure $\left.3 \mathrm{a}\right)$. The data and ISOFLOC results suggest a gradual 349 increase in the carbon source that delivered sediment carbon to the water column. The net 350 increase in fluvial carbon was not explained by annual benthic functioning controlled by 351 seasonal autochthonous growth followed by heterotrophic turnover that would favor a multi-year 352 equilibrium carbon signal (Ford and Fox, 2015). Nor was the net fluvial carbon increase 353 attributed to a shift in allochthonous carbon provenance because external carbon sources, 354 including agricultural surface soils and bank sediments, have relatively low carbon density $(\sim 2$ $355 \mathrm{gC} 100 \mathrm{gsoil}^{-1}$ ) in this basin (Ford et al., 2015). Rather, carbon isotope results reflect an accrual of 356 stabilized algal-originated carbon in the benthos, which was evident from the net decrease in the 357 sediment carbon isotope signature $\left(\delta^{13} C_{F P O C-T}\right)$ from early years (2006-2008) to later years 358 (2010-2013) for the eight year transported sediment carbon isotope dataset (Figure 3b). The 359 algal stabilization process is further supported based on literature comparison, in which the long360 term isotopic trend (Figure 3b) suggests a shift from terrestrial soil organic carbon (-25 to $-27 \%$ ) 361 to a mixture of terrestrial soil organic carbon and algal biomass ( -30 to $-35 \%$ ) (Kendall et al., 362 2001; Jacinthe et al., 2009; Ford et al., 2015). Interestingly, the accumulation of stabilized algal 363 carbon within the benthic sediment carbon pool known as the surficial fine grained laminae 
364 (SFGL) explains the downward shift in the transported sediment carbon isotope signature

$365\left(\delta^{13} C_{F P O C-T}\right)$. As was highlighted in the results, carbon sequestration via algal stabilization 366 occurs in the South Elkhorn watershed because annual input of algal carbon byproducts to the 367 streambed outweighed losses from particulate carbon erosion and microbial respiration (Tables 368 2-3). In summary, multiple lines of evidence point towards the prevalence of algal stabilization 369 with the agroecosystem stream over the study period.

371 due to algal stabilization is partially supported by recent studies on contemporary fluvial carbon 372 cycling and laboratory-scale investigations of algal stabilization (Lara and Thomas, 1995; 373 Regnier et al., 2013; Hotchkiss and Hall, 2015). Lara and Thomas (1995) used radio-labeled 374 carbon on batch cultures of an oceanic diatom to quantify stabilization dynamics and found 375 approximately $5 \%$ of the maximum carbon biomass was stabilized to recalcitrant humic 376 substances in the first month. Regnier et al. (2013) utilized a synthesis of published studies 377 focusing on the impact of anthropogenic disturbance to alter sequestration and fluxes of fluvial 378 organic carbon and showed that autochthonous $\mathrm{C}$ from inland waters is likely stored or exported 379 from inland freshwater systems at a rate of $~ 0.3$ PgC/year. Hotchkiss and Hall (2015) utilized a 380 carbon isotope tracer-based experiment to show that autochthonous $\mathrm{C}$ in a low order stream has 381 two distinct fates: either short-term exudation and respiration or longer-term storage and 382 downstream export. Despite the previous evidence of algal stabilization, no studies to our 383 knowledge have included this effort in watershed-scale fluvial organic carbon budgeting; 384 moreover, numerical models broadly neglect the fate of stabilized algae in the SFGL (Ford and 385 Fox, 2015). Findings from the present study suggest the potential importance of algal 386 stabilization to the fluvial carbon budget. Furthermore, the authors suggest numerical models, 
such as ISOFLOC, are effective tools for in-stream fluvial carbon budgeting including quantification of algal carbon fate and transport.

\subsection{Process and External Factors controlling Algal Stabilization:}

Results of the ISOFLOC scenario analysis for the South Elkhorn watershed provided insight into the role of biological and physical processes and how they impacted carbon sequestration due to algal stabilization at an annual timescale in streams draining agroecosystems. The small standard deviation of stabilized algae decomposition (Table 3) reflected the small deviation in temperature gradients from year to year, while the large standard deviation for stabilized algal erosion reflected two primary mechanisms. First, stabilized algal erosion can be shear limited and is thus directly impacted by the flow regime with higher flows having higher capacity to induce incipient motion. For instance, years with high annual precipitation (e.g., 2009) had highly stabilized algal erosion fluxes (e.g., $0.121 \mathrm{tC} \mathrm{km} \mathrm{kr}^{-2}$ ) whereas years with low precipitation (e.g., 2007) had substantially smaller algal FPOC fluxes (e.g., $0.054 \mathrm{tC} \mathrm{km}^{-2} \mathrm{yr}^{-1}$ ). Second, shielding of algal biomass due to large depositional fluxes during high magnitude storm events (i.e., the 100-year precipitation event in 2006) minimized stabilized algal erosion. ISOFLOC simulations showed low stabilized algae erosion during 2006, despite having high annual rainfall, which was a result of the large depositional flux during the September event. As a result, the stabilized algae was shielded from fluvial erosion because it was well mixed within a larger SFGL layer. Thus, the authors suggest that physical-hydrologic controls govern the variability of watershed source-sink capacity of carbon via algal stabilization at an annual scale. The yearly scale is particularly notable given that stream ecosystem and carbon transport studies often only consider seasonal and event variations of biologic and physical processes. 
Following from the controlling processes, at least two external factors controlled algal

411 stabilization in the stream and its maximum capacity, including high magnitude stochastic storm

412 events and subtler deterministic temperature shifts. As seen in Figure 5, removal of the subtle

413 temperature trend shown in Figure 2 resulted in less favorable conditions for algal stabilization

414 and thus a net decrease in SFGL C storage. For a residual temperature increase, both algae and

415 heterotrophic bacteria populations increased up to maximum saturation levels, e.g., population

416 limitations (White et al, 1991; Rutherford et al., 2000). Therefore, a residual temperature

417 increase promoted favorable conditions over longer timeframes for bacterial and algal

418 populations resulting in population maximums. Hence, when conditions for algal sequestration

419 occur for longer periods of the year, a chronic increase and buildup of stabilized algae in the

420 SFGL can occur. However, we note that this will approach a maximum due to a higher rate of

421 SFGL algal decomposition as compared to inputs from coarse algae as evidenced by the $2-4^{\circ} \mathrm{C}$

422 increase scenario in Figure 6. With regard to high magnitude, stochastic events, heavy 423 depositional fluxes provide a supply of terrestrial fine particulate organic carbon (Russo and Fox,

424 2012; Ford et al., 2014). Results in Figure 5d-f showed that removal of the 100-year 425 precipitation event resulted in a long-term residual decrease in stabilized algal carbon storage in 426 addition to a fairly stable annual transported sediment carbon content $\left(C_{F P O C-T}\right)$ and transported 427 sediment carbon isotope signature $\left(\delta^{13} C_{F P O C-T}\right)$ when compared with the baseline (calibrated) 428 condition. Collectively, findings from this study highlight the ability of external factors to 429 control maximum algal stabilization in the SFGL in which stochastic storm events governed how 430 far the SFGL deviates from maximum conditions (i.e., net zero carbon storage due to algal 431 stabilization), and long-term residual temperature changes provided a migrating maximum 432 capacity target. 


\subsection{Broader Implications:}

434

435

436

437

438

439

440

441

442

443

444

445

446

447

448

449

450

451

452

453

454

455

\subsubsection{Sensitivity to Temperature Shifts}

The findings of increased algal stabilization, when subjected to long-term temperature increases, contradict the emerging paradigm for response of stream ecosystem $\mathrm{C}$ dynamics to temperature changes. Broad-scale fluvial carbon research has shown the efficacy of fluvial systems to degass $\mathrm{CO}_{2}$ (Cole et al., 2007; Butman and Raymond, 2011). For example, US rivers are supersaturated with carbon dioxide when compared with the atmosphere, emitting $97 \pm 32 \mathrm{Tg}$ carbon each year (Butman and Raymond, 2011). Following with this assumption, recent results suggest that in the future, increasing temperature gradients will result in decreases of net ecosystem productivity by $13 \%$ since respiration by biota is suggested to be more sensitive to temperature than autotrophic production (Yvon Durocher et al., 2010). Conventional wisdom tends to neglect the ability of surface fine grained laminae to trap newly generated carbon within benthic sediments since studies typically assume fresh autochthonous carbon has short turnover lengths (Griffiths et al., 2012). Contradictory to conventional wisdom, results in Figure 6 suggested that the SFGL would sequester between 0 and $0.04 \mathrm{tC} \mathrm{km}^{-2}{ }^{\circ} \mathrm{C}^{-1}$ when subjected to a change in MAT. The range was due to the non-linearity of the benthic SFGL dynamics in which high temperature scenarios were approaching maximum sequestration capacity, and lower MAT subjected to temperature change was further from max capacity and hence stabilized algae at a higher rate.

The increased sequestration rate per ${ }^{\circ} \mathrm{C}$ temperature increase has significant implications for $\mathrm{C}$ budgets under potential warming scenarios projected by RCP simulations, which conservatively estimate a global $2^{\circ} \mathrm{C}$ temperature shift with a high of $4^{\circ} \mathrm{C}$ by 2100 . While studies have traditionally assumed a net zero effect of algal fixation due to high rates of turnover, recent 
456 estimates suggest $\sim 0.3 \mathrm{Pg}$ autochthonous $\mathrm{C} /$ year is either buried or exported from inland waters

457 (Cole et al., 2007; Regnier et al., 2013; Hotchkiss and Hall, 2015). To place our results in a

458 broader context, we extrapolated our findings globally assuming that agricultural systems have

459 non-rate limiting nutrient conditions, open canopies, and have comparable stream and hillslope

460 gradients, resulting in prominence of the SFGL layer. Assuming that there are approximately 60

461 million $\mathrm{km}^{2}$ of agricultural land, we find that changes in sequestration with respect to increases

462 in temperature could range from zero $\mathrm{Pg} /{ }^{\circ} \mathrm{C}$ for tropical climates where maximum stabilization

463 capacity of algae has been met or exceeded to upwards of $0.003 \mathrm{PgC} /{ }^{\circ} \mathrm{C}$ for cooler climatic

464 regions that currently have low algal stabilization. Thus, under a $4^{\circ} \mathrm{C}$ shift we could see the

465 balance of autochthonous $\mathrm{C}$ storage and burial dynamics increase by upwards of $4 \%$ as opposed

466 to the decrease in NEP of $13 \%$ that was observed in Trimmer et al. (2012). The finding

467 highlights the need for continued study of these disturbed systems in terms of in-stream $\mathrm{C}$ fate

468 and transport.

469

470

471

472

473

474

475

476

477

478

479

480

\subsubsection{Algal Sloughing to Downstream Ecosystems:}

While our findings to this point have focused on the role of stabilization for sequestering sediment carbon at the small watershed scale (e.g., $100 \mathrm{~km}^{2}$ ), these findings were conservative for total sequestration because the fate of the sloughed algal pool in receiving waterbodies had not been explicitly accounted for. Specifically, we were interested in how periphyton sloughing impacted the net annual storage of carbon due to algal stabilization and to assess the resultant implications for downstream waterbodies (Figure 7). In general, we found that algal storage and

sloughing were negatively correlated $\left(\mathrm{R}^{2}=0.6\right)$ with years of high sloughing $(2006,2009,2011$, and 2013) generally resulting in a net $\mathrm{C}$ storage near or below zero. Conversely, in years with low sloughing $\left(2007,2008,2010\right.$, and 2012), net $\mathrm{C}$ storage reached upwards of $0.1 \mathrm{tC} \mathrm{km}^{-2} \mathrm{yr}^{-1}$ 
481 which equated to approximately $15 \%$ of the sloughing flux in low sloughing years. This finding 482 suggested significant potential for sloughed periphyton stabilization to sequester carbon in 483 downstream reaches.

The significance of algal POC fluxes from small streams to downstream rivers and reservoirs has received little attention in the scientific literature but has significant implications 486 not only for carbon sequestration, but also nutrient release and oxygen uptake during turnover.

487 As a first attempt at quantifying the respective downstream fluxes, we upscaled our results and 488 compared periphyton produced in small streams to phytoplankton produced in the Kentucky 489 River, which is a series of slack water pools similar to other large rivers in the Midwest USA. To 490 compare the drainage area normalized sloughed periphyton fluxes to the fluxes of phytoplankton, 491 we utilized measurements of phytoplankton cell concentrations in the HUC 6 Kentucky river 492 shown in Figure 1 (Stevenson and White, 1995), converted those concentrations to organic C 493 equivalents (Menden-Deurer and Lassard, 2000), and estimated drainage area normalized fluxes 494 to downstream waterbodies utilizing a USGS gauging station near the confluence of the 495 Kentucky and Ohio rivers (USGS 03290500: Kentucky River at Lock 2, Lockport, KY). The 496 comparisons in Figure $7 \mathrm{~b}$ suggested that sloughed algal carbon from the small agroecosystem 497 streams are on the same order of magnitude, and in some years greater, than in situ 498 phytoplankton production on the Kentucky River. Despite the lack of study of stabilization 499 dynamics for periphyton that settles out in downstream waterbodies, the process' significance is 500 partially supported by large riverine studies where the deposition of labile organic matter has 501 been suggested to promote heterotrophic induced oxygen depletion (Ohte et al., 2007; 502 Stringfellow et al., 2009). While Ohte's and Stringfellows' studies focused on phytoplankton 503 turnover, their findings highlight the sensitivity of receiving water bodies to upstream algal 
504 dynamics. As such, future studies should consider implications of the periphyton stabilization

505 process. Future riverine models quantifying fluvial carbon budgets across scales need to

506 consider stabilization rates of both periphyton and phytoplankton algal pools jointly to better

507 constrain broad-scale estimates of inland autochthonous burial and transport.

Further, future studies that utilize ISOFLOC to determine downstream sloughing of algal

509 biomass should consider alternative mechanisms that could potentially impact benthic periphyton

510 stock and the fluvial carbon cycle. Of specific interest to periphyton sloughing is the $\mathrm{C}$ flux

511 associated with periphyton grazing by macroinvertebrates. Grazing has been highlighted as a

512 mechanism that can exert top-down control on periphyton, especially during mild temperature,

513 low biomass conditions (Rutherford et al., 2000). Since ISOFLOC does not explicitly consider

514 the impact of macroinvertebrate grazers on periphyton standing stocks, we find our estimates to

515 likely represent a high end of sloughing. However, for many streams draining agroecosystems,

516 we expect this impact to be low since the majority of sloughing occurs during high biomass and

517 high temperatures when grazers have been found to have minimal effects on the standing stock

518 of periphyton (Rutherford et al., 2000).

CONCLUSION

Findings from the South Elkhorn application of ISOFLOC and empirical mode

522 decomposition (EMD) of the eight-year dataset provided significant evidence of algal

523 stabilization to produce net sequestration of organic carbon in the surficial fine-grained laminae.

524 Based on ISOFLOC modelling results, the magnitude of stabilization is likely governed by 525 erosion-deposition dynamics and, to a lesser degree, temperature gradients. ISOFLOC scenario 
526 analysis of hydrologic controls suggested that significant deposition events had a shielding

527 effect, thereby minimizing the flux of stabilized algal carbon to downstream reaches. Scenario

528 analysis of biotic controls implied that increasing temperature gradients resulted in increases in

529 algal stabilization, which contradicts existing paradigms that point to decreases in net ecosystem

530 productivity due to microbial respiration. The authors finding of upwards of $15 \%$ of sloughed

531 periphyton to be stored during high residence time has significant implications for downstream

532 stabilization of algal biomass in large rivers and reservoirs. In conclusion, the authors suggest

533 algal stabilization has potentially significant implications for carbon sequestration in large-scale

534 carbon budgets and tools such as ISOFLOC can be used to successfully quantify this 535 stabilization.

537 ACKNOWLEDGEMENTS

We thank Dr. Harold Rowe for partial analysis of sediment elemental and isotope dataset.

539 We thank the numerous graduate and undergraduate students for data collection and sample 540 processing. We thank the University of Kentucky Department of Civil Engineering for partial 541 funding of the graduate student while at UK. We gratefully acknowledge financial support of 542 this research under National Science Foundation Award \#0918856 and Kentucky Science \& 543 Engineering Foundation Award \#2687-RDE-015. Finally, we would like to thank the editorial 544 board at Water Research and two anonymous reviewers, in particular Reviewer 1, whose 545 comments and hard work have helped improve the quality of the manuscript. 


\section{REFERENCES}

Butman, D., P.A. Raymond, (2011), Significant efflux of carbon dioxide from streams and rivers in the United States, Nat. Geosci., doi:10.1038/ngeo1294.

Chapra, S., G. Pelletier H. Tao (2008), QUAL2K: A Modeling Framework for Simulating River and Stream Water Quality, Version 2.11: Documentation and Users Manual, Civil and Environmental Engineering Dept., Tufts University, Medford, MA.

Cole, J., Y. Prairie N. Caraco W. McDowell, L. Tranvik, R. Striegl, C. Duarte, P. Kortelainen, J. Downing, J. Middelburg, J. Melack, (2007), Plumbing the global carbon cycle: Intergrating inland waters into the terrestrial carbon budget, Ecosystems, 10, 171-184, doi: 10.1007/s10021-006-9013-8.

Dalzell, B., T. Filley, J. Harbor, (2005), Flood pulse influences on terrestrial organic matter export from an agricultural watershed, Journal of Geophysical Reasearch, 110, G02011, doi: 10.1029/2005JG000043.

Davis, J.M., Baxter, C.V., Minshall, G.W., Olson, N.F., Tang, C., Crosy, B.T. 2013. Climateinduced shift in hydrological regime alters basal resource dynamics in a wilderness river ecosystem. Freshwater Biology, 58, 306-319, DOI: 10.1111/fwb.12059.

DiToro, D.M., (2001), Sediment Flux Modeling, John Wiley and Sons, Hoboken, New Jersey.

Dodds, W.K., (2007), Trophic state, eutrophication and nutrient criteria in streams, Trends in Ecology and Evolution, 22(12), 669-676, doi: 10.1016/j.tree.2007.07.010.

Droppo, I., M. Stone, (1994), In-channel surficial fine grained sediment lamina. Part I: Physical Characteristics and formational processes,. Hydrological Processes, 8, 101-111, doi: 10.1002/hyp.3360080202.

Flynn, K.F., S.C. Chapra, M.W. Suplee (2013), Modeling the lateral variation of bottom-attached algae in rivers, Ecological Modeling, 267, 11-25.

Ford, W.I., J.F. Fox, (2014a), Model of particulate organic carbon transport in an agriculturally impacted stream, Hydrol. Process., 28(3), 662-675, doi: 10.1002/hyp.9569.

Ford, W.I., J.F. Fox, (2014b), Benthic control on the statistical distribution of transported sediment carbon in a low-gradient stream, Journal of Hydrology, 515, 316-329, doi: 10.1016/j.jhydrol.2014.05.012.

Ford, W.I., J.F. Fox, (2015) Isotope-based fluvial organic carbon (ISOFLOC) model: model formulation, sensitivity, and evaluation, Water Resources Research, 51, 4046-4064, doi:10.1002/2015WR016999.

Ford, W.I., J.F. Fox, H. Rowe (2014), Impact of extreme hydrologic disturbance upon the sediment carbon quality in agriculturally-impacted temperate streams, Ecohydrology, In Press, DOI : 10.1002/eco.1514

Ford, W.I., J.F. Fox, E. Pollock, H. Rowe, S. Chakraborty. (2015), Testing assumptions for nitrogen transformation in a low-gradient agricultural stream, Journal of Hydrology, 527, 908-922, doi:10.1016/j.hydrol.2015.05.062.

Fovet, O., G. Belaud, X. Litrico, S. Charpentier, C. Bertrand, A. Dauta, C. Hugodot, (2012), Modelling periphyton in irrigation canals, Ecological Modeling, 221, 1153-1161, doi: 10.1016/j.ecolmodel.2010.01.002.

Fox, J., Davis, C., Martin, D., 2010. Sediment source assessment in a lowland watershed using nitrogen stable isotopes. Journal of American Water Resources Association, 46, 11921204. 
Fox, J., W.I. Ford, K. Strom, G. Villarini, M. Meehan, (2014), Benthic control upon the morphology of transported fine sediments in a low-gradient stream, Hydrological Processes, In Press, DOI: 10.1002/hyp.9928.

Graba, M., S. Sauvage, F.Y. Moulin, G. Urrea, S. Sabater, J.M. Sanchez-Perez, (2013), Interaction between local hydrodynamics and algal community in epilithic biofilm, Water Research, 47, 2153-2163, doi: 10.1016/j.watres.2013.01.011.

Griffiths, N.A., J.L. Tank, T.V. Royer, T.J. Warrner, T.C. Frauendorf, E.J. Rosi-Marshall, M.R. Whiles, (2012), Temporal variation in organic carbon spiraling in Midwestern agricultural streams, Biogeochemistry, 108, 149-169, doi: 10.1007/s10533-011-9585-z.

Hotchkiss, E., R.O. Hall, (2015), Whole-stream 13C tracer addition reveals distinct fates of newly fixed carbon. Ecology, 96(2): 403-416.

Huang, N.E., Shen, Z., Long, S.R., Wu, M.C., Shih, H.H., Zheng, Q., Yen, N., Tung, C.C., Liu, H.H., 1998. The empirical mode decomposition and the Hilbert spectrumfor nonlinear and non-stationary time series analysis. Proceedings: Mathematical, Physical and Engineering Sciences, 454(1971), 903-995.Kendall, C., Silva, S.R., Kelly, V.J., 2001. Carbon and nitrogen isotopic compositions of particulate organic matter in four large river systems across the United States. Hydrological Processes, 15, 1301-1346, DOI: 10.1002/hyp.216.

Jacinthe, P.A., R. Lal, L.B. Owens, (2009), Application of stable isotope analysis to quantify retention of eroded carbon in grass filters at the North Appalachian experimental watersheds, Geoderma, 148, 405-412, doi: 10.1016/j.geoderma.2008.11.013.

Kendall, C., R. Silva, V.J. Kelly, (2001), Carbon and nitrogen isotopic compositions of particulate organic matter in four large river systems across the United States. Hydrol. Process., 15, 1301-1346.

Lara, R.J., D.N. Thomas, (1995), Formation of recalcitrant organic matter: humification dynamics of algal derived dissolved organic carbon and its hydrophobic fractions. Marine Chemistry, 51: 193-199.

Leloup, M., R. Nicolau, V. Pallier, C. Yepremian, G. Feuillade-Cathalifaud, (2013), Organic matter produced by algae and cyanobacteria: Quantitative and qualitative characterization. Journal of Environmental Sciences, 25(6): 1089-1097.

Menden-Deurer, S., and E.J. Lassard, (2000), Carbon to volume relationships for dinoflagellates, diatoms, and other protist plankton, Limnol. Oceanogr., 45(3), 569-579.

Minshall GW, Petersen RC, Cummins KW, Bott TL, Sedell JR, Cushing CE, Vannote RL. 1983. Interbiome comparison of stream ecosystem dynamics. Ecological Monographs 53(1):225.

Moriasi, D.N., J.G. Arnold, M.W. Van Liew, R.L. Bingner, R.D. Harmel, T.L. Veith, (2007), Model evaluation guidelines for systematic quantification of accuracy in watershed simulations, Transactions of the ASABE, 50(3), 885-900, doi: 10.13031/2013.23153.

Ohte, N., S. Silva, C. Kendal, C. Kratzer, R. Dahlgren, D. Doctor, (2007), Sources and transport of algae and nutrients in a Californian river in a semi-arid climate, Freshwater Biology, 2007, 12, 2476-2493, doi: 10.1111/j.1365-2427.2007.01849.x.

Park, R.A., J.S. Clough, (2012), AQUATOX (Release 3.1) Modeling environmental fate and ecological effects in aquatic ecosystems, U.S. EPA, Washington, DC.

Peterson, C. G. (1996) Response of benthic algal communities to natural physical disturbance. Pages 375-402, In (R. J. Stevenson, M. L. Bothwell, \& R. L. Lowe, editors) Algal Ecology: Freshwater Benthic Ecosystems. Academic Press, San Diego. 
Phillips, J., Russell, M., Walling, D., 2000. Time-integrated sampling of fluvial suspended sediment: a simple methodology for small catchments. Hydrological Processes, 14, 2589-2602.

Regnier, P. et al. Anthropogenic perturbation of the carbon fluxes from land to ocean. Nature Geosci. 6, 597-607 (2013).

Russo, J., J.F. Fox, (2012), The role of the surface fine-grained laminae in low-gradient streams: A model approach. Geomorphology, 171-172: 127-138.

Rutherford, J., M. Scarsbrook, N. Broekhuizen, (2000), Grazer control of stream algae: modeling temperature and flood effects, Journal of Environmental Engineering, 126, 331-339, doi: 10.1061/(ASCE)0733-9372(2000)126:4(331).

Salteli A.S., P. Annoni, I. Azzini, F. Campolongo, M. Ratto, S. Tarantola, (2010), Variance based sensitivity analysis of model output. Design and estimator for the total sensitivity index, Computer Physics Communications, 181, 259-270.

Sobol' I.M., (2001), Global sensitivity indices for nonlinear mathematical models and their Monte Carlo estimates, Mathematics and Computers in Simulation, 55, 271-280.

Stevenson, R.J., K.D. White, (1995), A comparison of natural and human determinants of phytoplankton communities in the Kentucky River basin, USA. Hydrobiologia, 297, 201 216.

Stringfellow, W., J. Herr, G. Litton, M. Brunell, S. Borglin, J. Hanlon, C. Chen, J. Graham, R. Burks, R. Dahlgren, C. Kendall, R. Brown, N. Quin, (2009), Investigation of river eutrophication as part of a low dissolved oxygen total maximum daily load implementation, Water Science and Technology, 59.1, doi: 10.2166/wst.2009.739.

Trimmer, M. J. Grey, C.M. Heppell, A.G. Hildrew, K. Lansdown, H. Strahl, G. Yvon-Durocher, (2012), River bed carbon and nitrogen cycling: State of play and some new directions, Sci. Tot. Environ., 434, 143-158.

Verardo, D.J., Froelich, P.N., McIntyre, A., 1990. Determination of organic carbon and nitrogen in marine sediments using the Carlo Erba NA-1500 Analyzer. Deep-Sea Research, 37 (1), 157-165.

White, P., J. Kalff, J. Rasmussen, J. Gasol, (1991), The effect of temperature and algal biomass on bacterial production and specific growth rate in freshwater and marine habitats, Microbial Ecology, 21, 99-118.

Wool, T.A., R.B. Ambrose, J.L. Martin, E.A. Comer, (2006), Water Quality Analysis Simulation Program (WASP), Version 6, U.S. EPA, Washington, DC.

Wu, Z., Huang, N.E., Peng, C., 2007. On the trend, detrending, and variability of nonlinear and nonstationary time series. Proceedings of the National Academy of Sciences, 104(38), 14889-14894.

Yvon-Durocher G., J.M. Montoya, G. Woodward, J.J. Jones, M. Trimmer, (2011), Warming increases the proportion of primary production emitted as methane from freshwater mesocosm, Global Change Biology, 17, 1225-1234. 


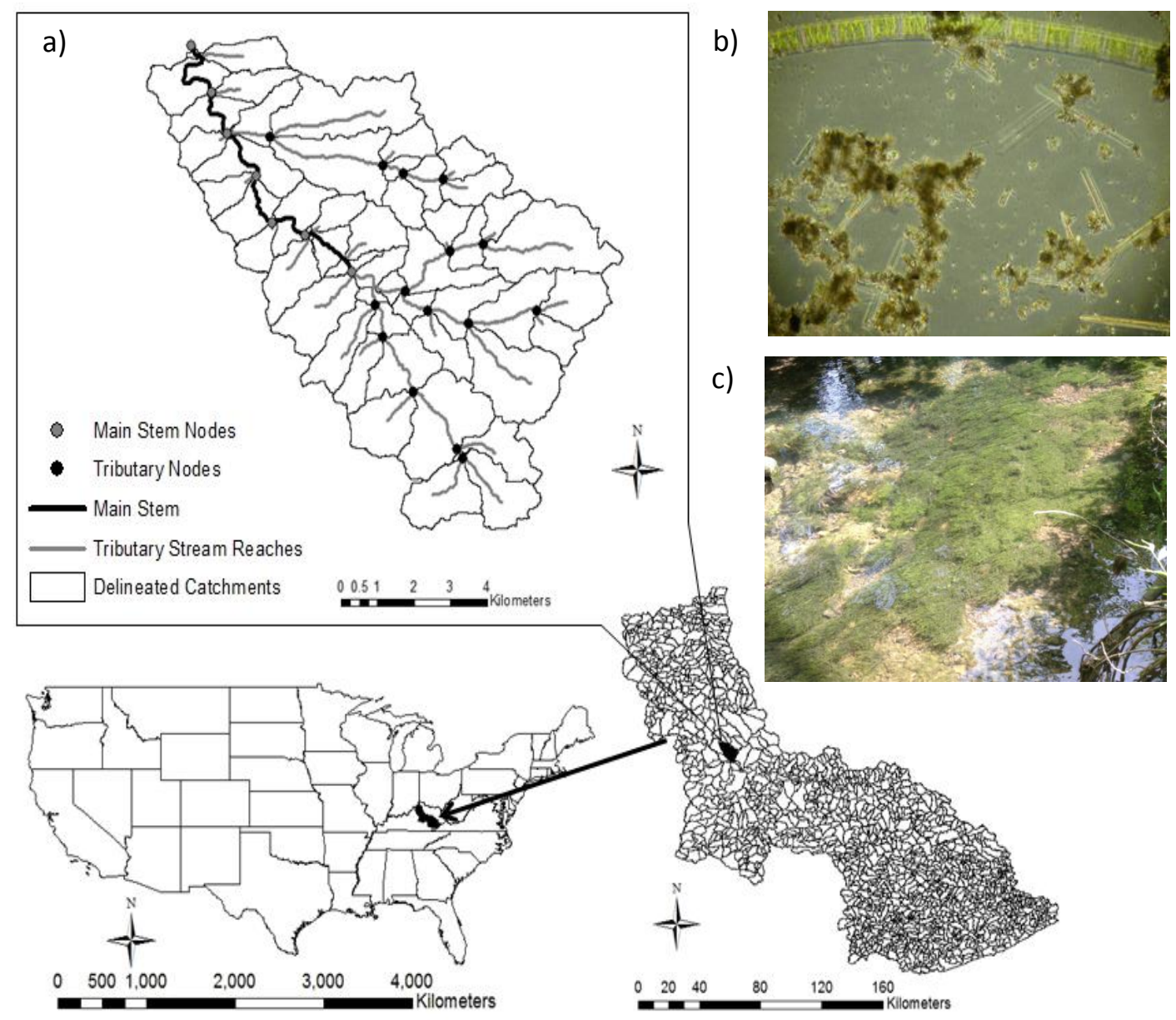

676

677 Figure 1) The figure displays (a) the South Elkhorn study site and ISOFLOC model domain 678 located in Kentucky, USA within the Kentucky River Basin, (b) microscopy analysis of 679 transported sediment aggregates at the watershed outlet highlighting the prominence of 680 autotrophic organisms in transport, and (c) study site image of periphytic algal mats commonly 681 observed in the benthos of the South Elkhorn. 

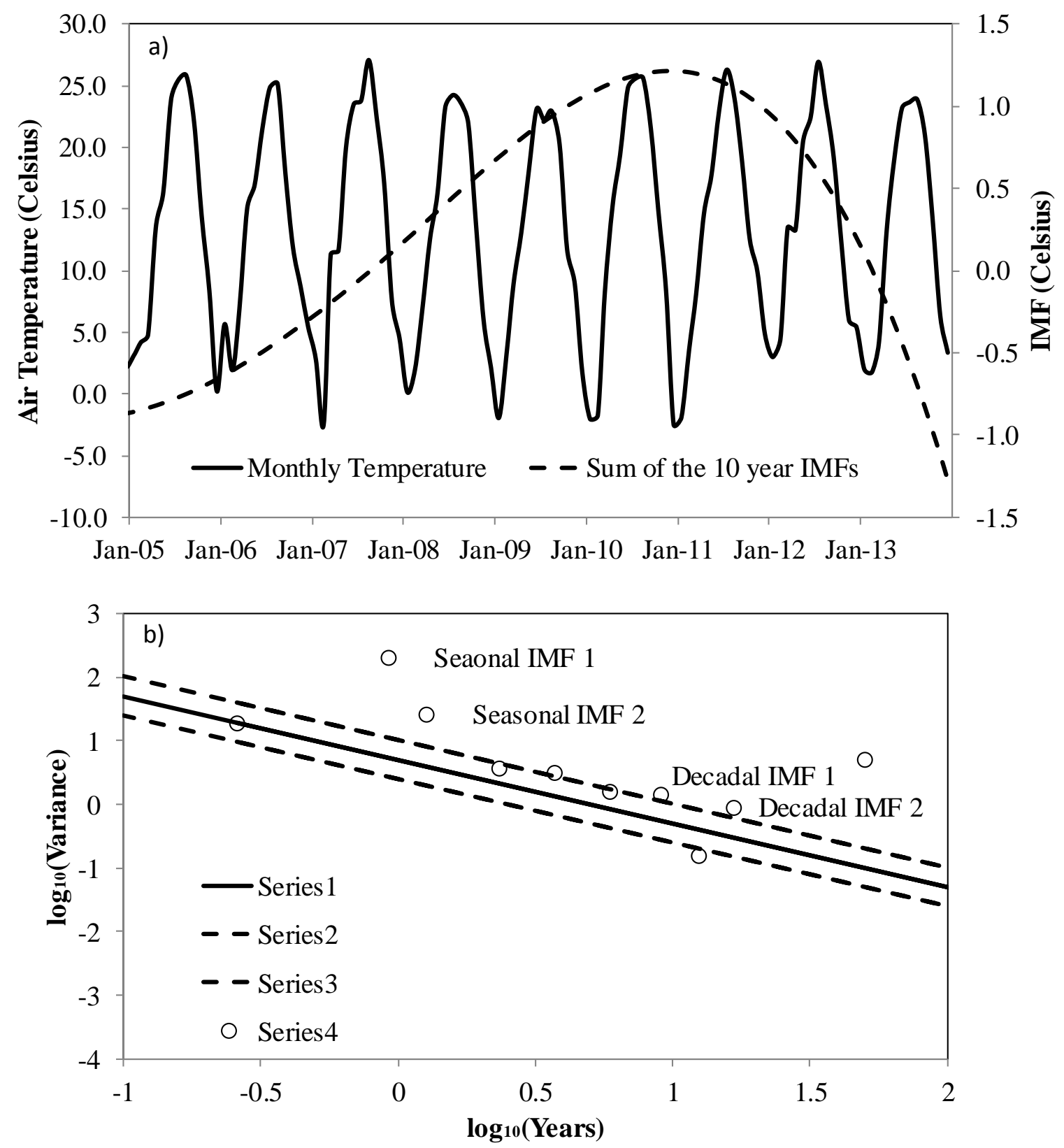

684

685

686

687

688

689

690
Figure 2. EMD Analysis of 40 year Time-series of monthly temperature at the Bluegrass Regional Airport in Lexington, KY. Chart includes raw timeseries, statistically significant seasonal IMFs and statistically significant decadal IMFs. Long-term residual trend is relatively stationary. 

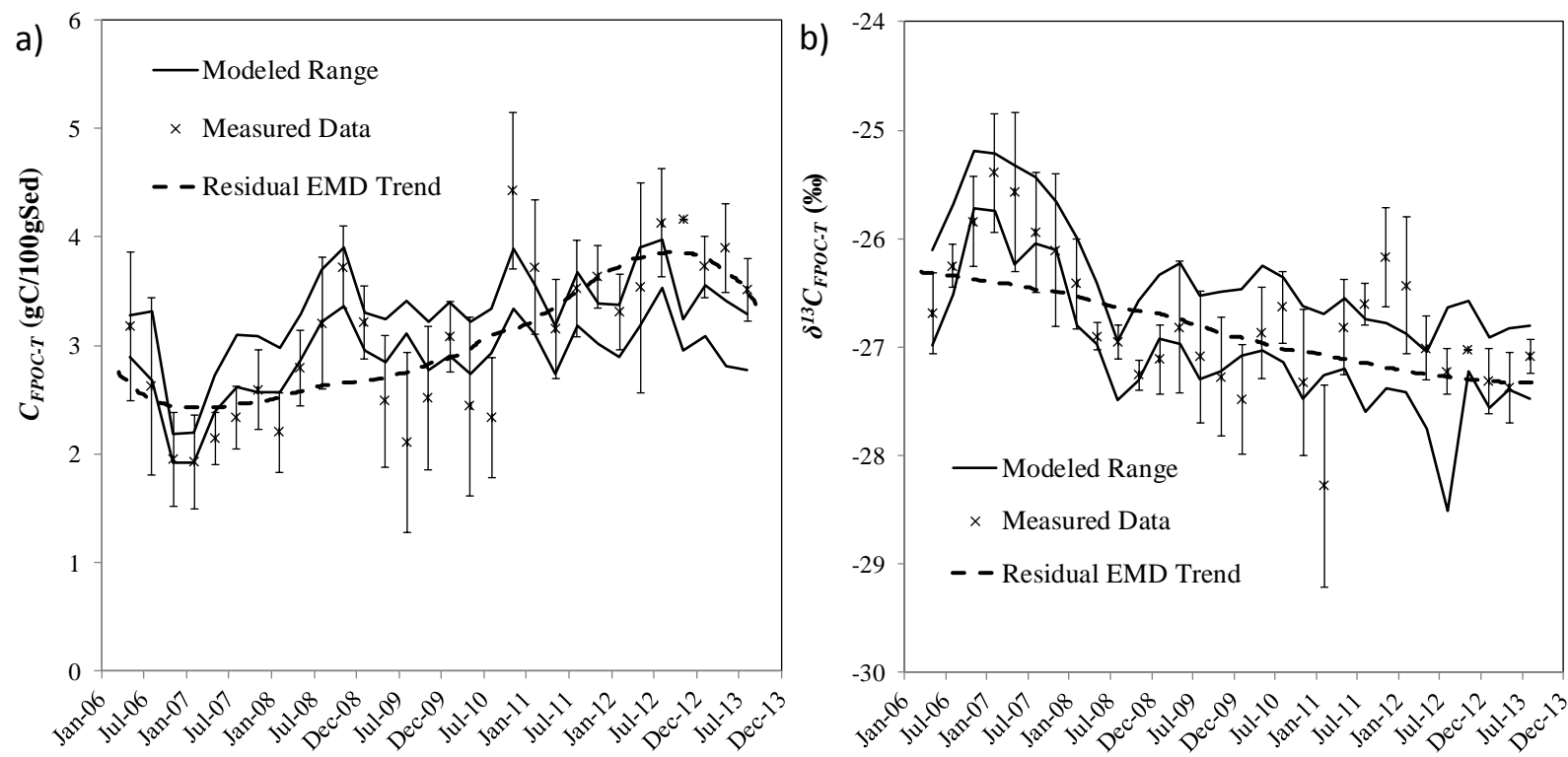

692 Figure 3.Time-series of monthly averaged data \pm 1 S.D., calibrated model output, and the 693 residual IMFs from the empirical mode decomposition for a) transported sediment carbon 694 content $\left(C_{F P O C-T}\right)$ and b) stable carbon isotopic signature of transported sediment carbon $695\left(\delta^{13} C_{\text {FPOC-T }}\right)$.

696

697 

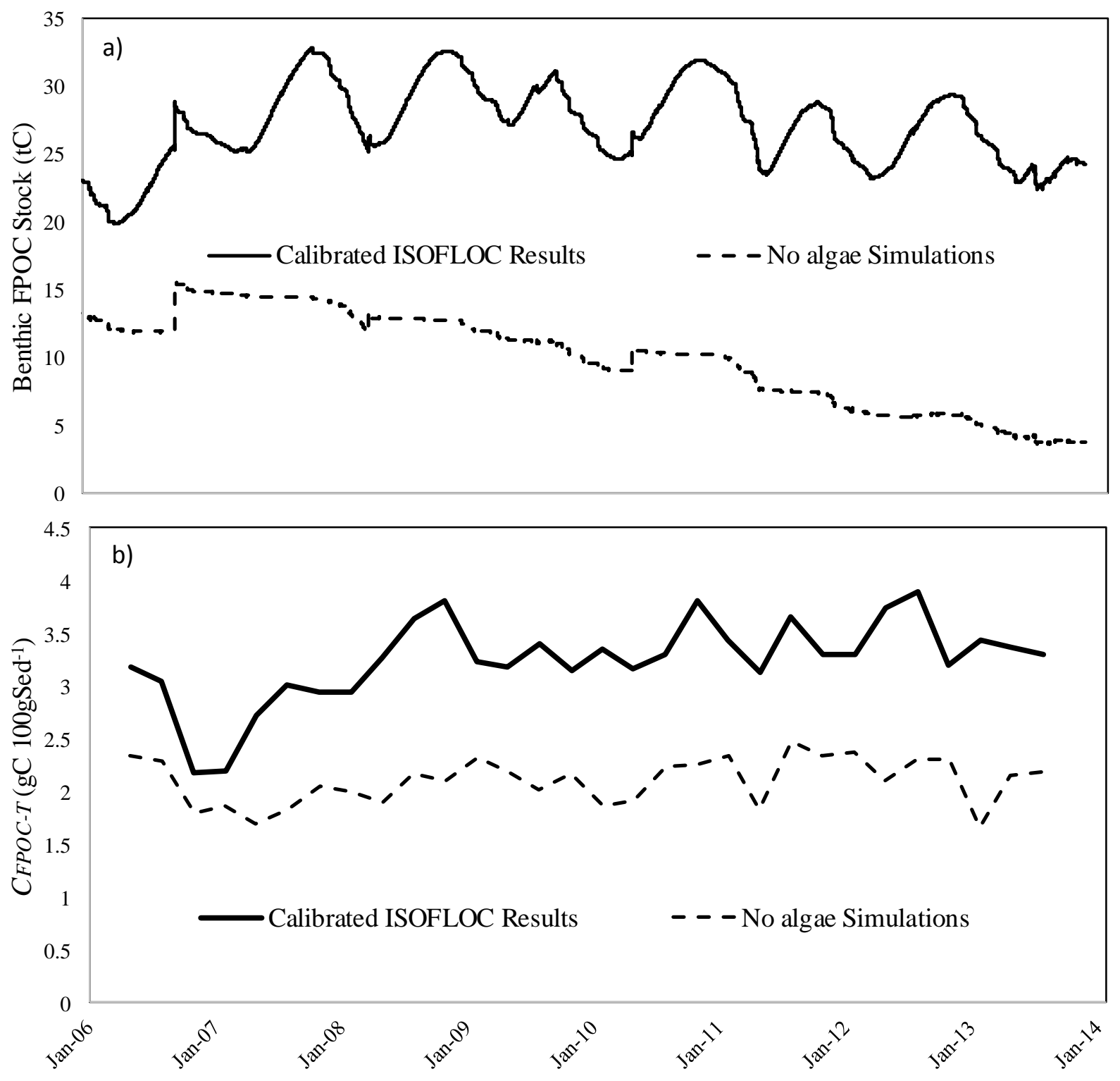

Figure 4) (a) Benthic carbon stock and (b) transported $\mathrm{C}_{\mathrm{FPOC}-\mathrm{T}}$ for the optimized model scenario 700 and a secondary simulation which set maximum algal biomass $\left(\mathrm{P}_{\text {Max }}\right)$ to zero (i.e., no algae 701 simulations). 

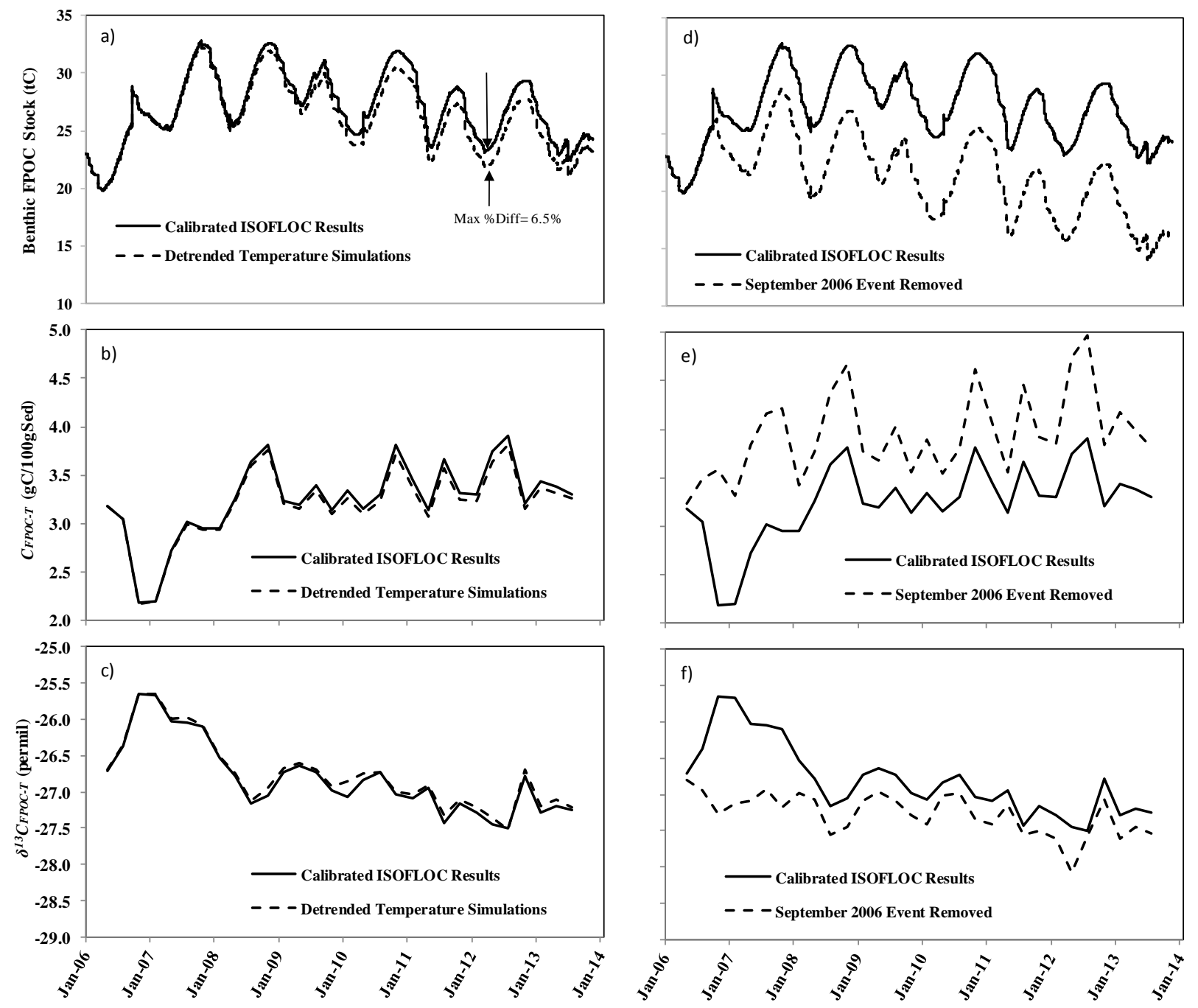

Figure 5. ISOFLOC parameterization for the optimized model run (e.g., NSE $>0.4, \mathrm{RSR}<0.8$, PBIAS <10\%) for both calibration and validation was utilized to run a suite of tests to tease out causes for long-term increases in SFGL carbon. Results are included for the response of SFGL carbon stock $(\mathrm{a}, \mathrm{d})$ and the response variable $\left(C_{F P O C-T}\right)(\mathrm{b}, \mathrm{e})$ and the stable carbon isotope response variable transported sediment carbon isotope signature $\left(\delta^{13} C_{F P O C-T}\right)(\mathrm{c}, \mathrm{f})$. Further, results are included for two suggested drivers of long-term variability of long-term residual temperature increases (a-c) and extreme events (d-f). 


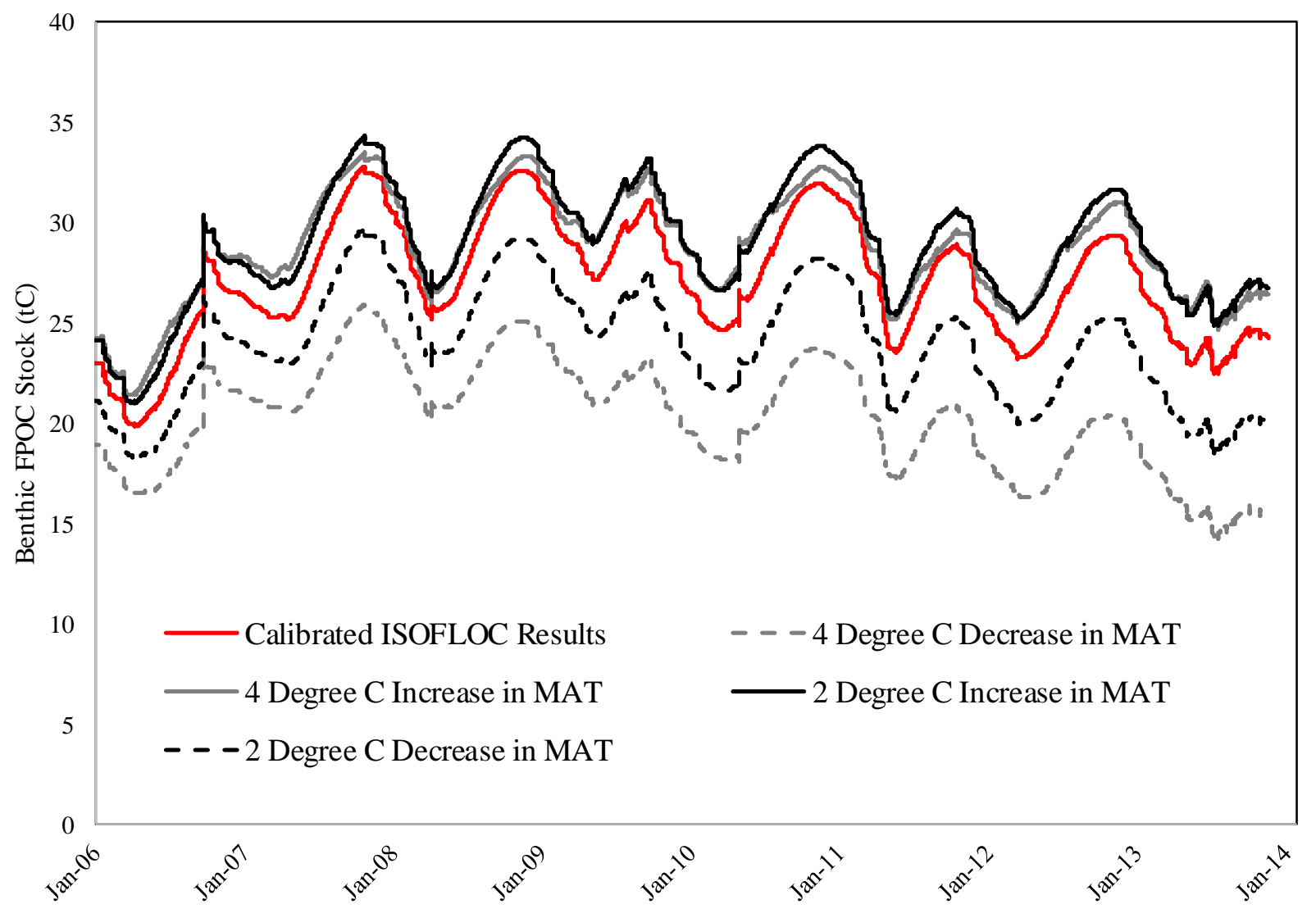

Figure 6. Benthic carbon accrual in response to shifts in mean annual temperature assuming a 2 and 4 degree increase (decrease) in temperature. The analysis eludes to the potential sensitivity of processes subjected to different climatic conditions and subjected to shifts in mean annual temperatures for the local watershed (assuming other calibrated parameters hold). 

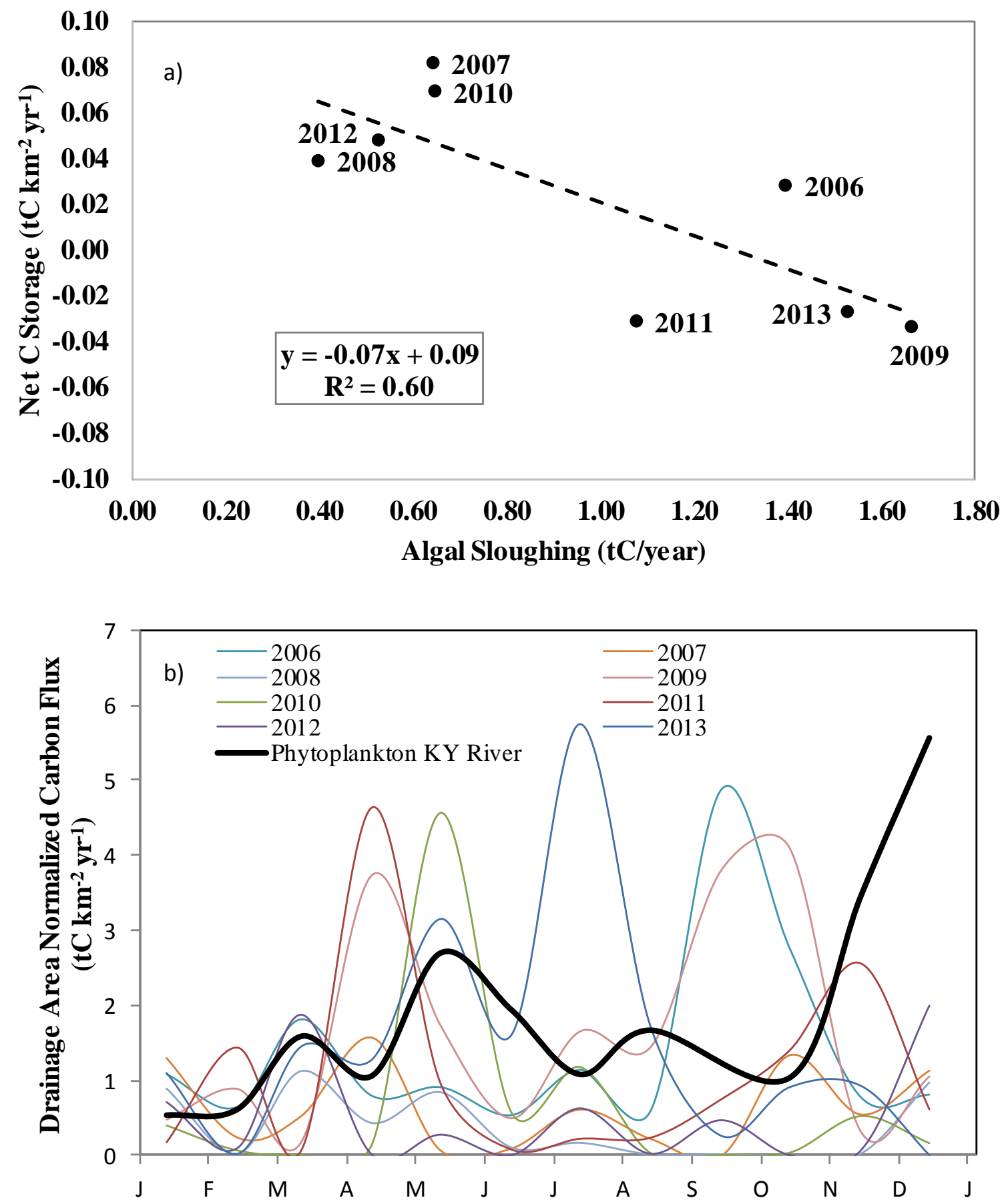

722 Figure 7) (a) Sloughing of periphyton vs. storage of algal carbon for optimum model scenario 723 and (b) comparison of sloughed periphyton vs. phytoplankton in the Kentucky River utilizing 724 results from ISOFLOC 
Table 1) Model parameterization table with parameter identifiers, parameter descriptions, calibrated values, and uncertainty ranges PBIAS $<10 \%$ for all calibration/validation scenarios) is highlighted in bold.

\begin{tabular}{|c|c|c|c|c|}
\hline Parameter ID & Parameter Description & Calibrated Value & Uncertainty Range & Units \\
\hline$\tau_{c r}^{\text {algae }}$ & Algal critical shear stress & 1.12 & $0.76-1.63$ & $\mathrm{~Pa}$ \\
\hline$P_{c o l}$ & Algal colonization rate & 6.73E-05 & $1.49 \mathrm{E}-05-6.73 \mathrm{E}-05$ & $\mathrm{kgC} \mathrm{m}^{-2} \mathrm{~d}^{-1}$ \\
\hline$P_{\text {Max }}$ & Max algae fixation rate & 2.34E-03 & $5.25 \mathrm{E}-04-3.12 \mathrm{E}-03$ & $\mathrm{kgC} \mathrm{m}^{-2} \mathrm{~d}^{-1}$ \\
\hline$D E C_{F P O C-A l g a e}$ & Decomposition of fine to dissolved algal carbon & 3.44 & $3.26-3.77$ & $d^{-1}$ \\
\hline$d_{S F G L}$ & Depth of the SFGL & 9.74E-03 & $5.44 \mathrm{E}-03-9.98 \mathrm{E}-03$ & $\mathrm{~m}$ \\
\hline$C_{\text {Upland }}$ & Carbon content of hillslope sediments & 2.68E-02 & $0.023-0.031$ & 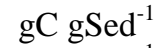 \\
\hline$C_{\text {Bank }}$ & Carbon content of bank sediments & 1.77E-02 & $0.010-0.019$ & 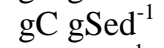 \\
\hline$C_{D I C-I N}$ & Concentration of dissolved inorganic carbon in tributaries & 8.21E-02 & $0.029-0.084$ & $\mathrm{mgC} \mathrm{L}^{-1}$ \\
\hline$\delta^{13} C_{D I C-I N}$ & Isotopic signature of inflowing dissolved inorganic carbon & -14.7 & $-14.7--10.7$ & $\%$ \\
\hline$\delta^{13} C_{\text {Upland }}$ & Isotopic signature of hillslope sediment carbon & -27 & $-27.3--26.1$ & $\%$ \\
\hline$\delta^{13} C_{\text {Bank }}$ & Isotopic signature of bank sediment carbon & -24.1 & $-25.7--23.9$ & $\%$ \\
\hline$\delta^{13} C_{\text {Atmosphere }}$ & Isotopic signature of atmospheric $\mathrm{CO}_{2}$ & -7.09 & $7.11-8.54$ & $\%$ \\
\hline$\varepsilon_{D E C-F P O C}$ & Decomposition of fine sediment carbon isotope fractionation & 0.95 & $0.01-1.99$ & $\%$ \\
\hline$\varepsilon_{D E C-A P O C}$ & Fractionation associated with decomposing algae & 1.73 & $0.08-1.76$ & $\%$ \\
\hline$\varepsilon_{\text {Assimilation-Max }}$ & Maximum fractionation associated with algal carbon fixation & 19 & $16.5-23.8$ & $\%$ \\
\hline$w_{\mathrm{CO} 2}$ & Gas transfer velocity of $\mathrm{CO}_{2}$ & 3.84E-05 & $3.75 \mathrm{E}-05-6.87 \mathrm{E}-05$ & $\mathrm{~m} \mathrm{~s}^{-1}$ \\
\hline Pre & Precipitation of particulate inorganic carbon & 3.31E-08 & 8.7E-09-6.02E-08 & $\mathrm{kgC} \mathrm{m}^{-2} \mathrm{~s}^{-1}$ \\
\hline Dis & Dissolution of particulate inorganic carbon & 1.18E-08 & $1.3 \mathrm{E}-09-1.54 \mathrm{E}-08$ & $\mathrm{kgC} \mathrm{m}^{-2} \mathrm{~s}^{-1}$ \\
\hline$P_{\text {resp }}$ & Respiration rate of the algal mat & 0.12 & $0.04-0.15$ & $\mathrm{~d}^{-1}$ \\
\hline
\end{tabular}


731 Table 2) Fluvial organic carbon budget results for the eight year ISOFLOC simulation in the 732 South Elkhorn Watershed. Fluxes and storage terms are normalized by watershed area. Values 733 are provided for the optimum scenario.

\begin{tabular}{cccccc}
\hline \multicolumn{7}{c}{ Net Humified Algal Carbon Storage $(\mathbf{t C} \mathbf{~ k m}-2)$} \\
\hline $\mathbf{2 0 0 6}$ & Winter & Spring & Summer & Fall & Annual \\
$\mathbf{2 0 0 7}$ & -0.033 & 0.038 & 0.039 & -0.021 & 0.023 \\
$\mathbf{2 0 0 8}$ & -0.013 & 0.049 & 0.066 & -0.022 & 0.080 \\
$\mathbf{2 0 0 9}$ & -0.056 & 0.023 & 0.069 & -0.005 & 0.032 \\
$\mathbf{2 0 1 0}$ & -0.034 & 0.005 & 0.028 & -0.046 & -0.046 \\
$\mathbf{2 0 1 1}$ & -0.021 & 0.025 & 0.061 & 0.000 & 0.065 \\
$\mathbf{2 0 1 2}$ & -0.047 & -0.020 & 0.057 & -0.036 & -0.045 \\
$\mathbf{2 0 1 3}$ & -0.031 & 0.046 & 0.044 & -0.018 & 0.042 \\
Average & -0.046 & 0.000 & 0.007 & -0.003 & -0.043 \\
& -0.035 & 0.021 & 0.046 & -0.019 & 0.013 \\
\hline
\end{tabular}

\begin{tabular}{|c|c|c|c|c|c|}
\hline \multicolumn{6}{|c|}{ Humified Algal Carbon Flux $\left(\mathrm{tC} \mathrm{km}^{-2}\right)$} \\
\hline & Winter & Spring & Summer & Fall & Annual \\
\hline 2006 & 0.029 & 0.013 & 0.030 & 0.019 & 0.091 \\
\hline 2007 & 0.011 & 0.007 & 0.007 & 0.029 & 0.054 \\
\hline 2008 & 0.043 & 0.015 & 0.003 & 0.012 & 0.073 \\
\hline 2009 & 0.024 & 0.029 & 0.030 & 0.038 & 0.121 \\
\hline 2010 & 0.014 & 0.019 & 0.008 & 0.006 & 0.047 \\
\hline 2011 & 0.034 & 0.045 & 0.010 & 0.035 & 0.125 \\
\hline 2012 & 0.025 & 0.004 & 0.018 & 0.020 & 0.067 \\
\hline 2013 & 0.033 & 0.034 & 0.047 & 0.014 & 0.129 \\
\hline Average & 0.027 & 0.021 & 0.019 & 0.022 & 0.088 \\
\hline \multicolumn{6}{|c|}{ Periphyton Carbon Flux (tC km-2) } \\
\hline & Winter & Spring & Summer & Fall & Annual \\
\hline 2006 & 0.294 & 0.185 & 0.548 & 0.365 & 1.393 \\
\hline 2007 & 0.173 & 0.142 & 0.071 & 0.253 & 0.639 \\
\hline 2008 & 0.174 & 0.117 & 0.018 & 0.085 & 0.395 \\
\hline 2009 & 0.126 & 0.496 & 0.576 & 0.464 & 1.197 \\
\hline 2010 & 0.038 & 0.446 & 0.101 & 0.058 & 0.644 \\
\hline 2011 & 0.128 & 0.467 & 0.098 & 0.380 & 1.073 \\
\hline 2012 & 0.232 & 0.024 & 0.093 & 0.175 & 0.524 \\
\hline 2013 & 0.217 & 0.485 & 0.672 & 0.153 & 1.526 \\
\hline Average & 0.173 & 0.295 & 0.272 & 0.242 & 0.982 \\
\hline
\end{tabular}

734

735 
736 Table 3) ISOFLOC simulation of algal FPOC dynamics in the South Elkhorn watershed 737 including fluxes into (periphyton decomposition) and out (algal SFGL decomposition and 738 erosion) of the SFGL. Results are provided for the calibrated scenario.

\begin{tabular}{|c|c|c|c|c|}
\hline Year & $\begin{array}{c}\text { Periphyton } \mathrm{C} \\
\text { Decomposition } \\
\left(\mathrm{tC} \mathrm{km}^{-2}\right)\end{array}$ & $\begin{array}{l}\text { Humified Algal } \\
\text { C Decomposition } \\
\left(\mathrm{tC} \mathrm{km} \mathbf{~ k m}^{-2}\right)\end{array}$ & $\begin{array}{c}\text { Humified Algal } \\
\text { C Erosion } \\
\left(\mathrm{tC} \mathrm{km} \mathbf{~ k m}^{-2}\right)\end{array}$ & $\begin{array}{c}\text { Net Humified C } \\
\text { Storage } \\
(\mathrm{tC} \mathrm{km-2})\end{array}$ \\
\hline 2006 & 0.172 & 0.058 & 0.091 & 0.023 \\
\hline 2007 & 0.215 & 0.082 & 0.054 & 0.080 \\
\hline 2008 & 0.191 & 0.086 & 0.073 & 0.032 \\
\hline 2009 & 0.164 & 0.090 & 0.121 & -0.046 \\
\hline 2010 & 0.205 & 0.093 & 0.047 & 0.065 \\
\hline 2011 & 0.173 & 0.094 & 0.125 & -0.045 \\
\hline 2012 & 0.210 & 0.102 & 0.067 & 0.041 \\
\hline 2013 & 0.170 & 0.083 & 0.129 & -0.042 \\
\hline Total & 1.500 & 0.687 & 0.706 & 0.107 \\
\hline Average & 0.188 & 0.086 & 0.088 & 0.013 \\
\hline Std Dev & 0.020 & 0.013 & 0.033 & 0.051 \\
\hline
\end{tabular}

